\title{
Pentingnya Mengoptimalkan Evaluasi Budaya Keselamatan Pasien
}

\section{Try Ayu Amanda Pasaribu}

\section{trvavuamanda08@gmail.com}

\section{LATAR BELAKANG}

Rumah sakit merupakan institusi pelayanan kesehatan yang menyelenggarakan pelayanan kesehatan perorangan serta paripurna. Rumah Sakit menyediakan pelayanan rawat inap, rawat jalan, dan gawat darurat. Rumah Sakit diselenggarakan dengan asas Pancasila dan berdasarkan pada nilai kemanusiaan, etika dan profesionalitas, manfaat, keadilan, persamaan hak, anti diskriminasi, pemerataan, perlindungan serta keselamatan pasien, serta mempunyai fungsi sosial. Dalam hal aspek keselamatan pasien, Rumah Sakit wajib untuk menerapkan standar keselamatan pasien. Standar keselamatan pasien dilakukan melalui pelaporan insiden, analisis dan pemecahan berbagai masalah sebagai upaya untuk menurunkan angka kejadian yang tidak diharapkan. Keselamatan pasien Rumah Sakit adalah system asuhan pasien berupa penilaian risiko, identifikasi dan manajemen risiko pasien, pelaporan dan analisis insiden, kemampuan belajar dari insiden dan tindak lanjutnya, serta implementasi solusi untuk meminimalkan timbulnya risiko dan mencegah terjadinya cedera yang disebabkan oleh kesalahan akibat melaksanakan suatu tindakan atau tidak mengambil tindakan yang seharusnya diambil.

Keselamatan pasien (Patient Safety) merupakan isu global dan nasional bagi rumah sakit, komponen penting dari mutu layanan kesehatan, prinsip dasar dari pelayanan pasien dan komponen kritis dari manajemen mutu. Keselamatan pasien di rumah sakit merupakan suatu sistem di rumah yang menjamin bahwa asuhan pasien lebih aman.Keselamatan pasien merupakan bagian yang harus diupayakan dalam peningkatan mutu pelayanan kesehatan di Rumah Sakit. Salah satu indikator keselamatan pasien adalah meningkatkan keamanan obatobatan yang harus diwaspadai, akan tetapi kesalahan administrasi obat menjadi masalah utama di rumah sakit yang perlu diupayakan penyelesaiannya.

Konsep mengenai budaya keselamatan pasien menjadi poin penting dalam organisasi pelayanan kesehatan, karena dengan mempertahankan budaya keselamatan pasien maka budaya keselamatan pasien akan baik. Keselamatan pasien merupakan masalah krusial bagi rumah sakit. Keselamatan pasien juga merupakan prinsip fundamental dari perawatan pasien, yang merupakan komponen penting dari manajemen mutu pelayanan kesehatan. Penerapan 
program keselamatan pasien lebih efektif dibandingkan dengan faktor-faktor lain dalam menurunkan angka kejadian insiden keselamatan pasien.

Keamanan pelayanan di Rumah Sakit dimulai dari ketepatan identifikasi pasien. Rumah Sakit harus membangun sistem yang menjamin bahwa pelayanan yang tepat diberikan kepada pasien yang tepat. Keselamatan pasien merupakan pencegahan cidera terhadap pasien. pencegahan cedera didefinisikan bebas dari bahaya yang terjadi dengan tidak sengaja atau dapat dicegah sebagai hasil perawatan medis. praktek keselamatan pasien adalah mengurangi risiko kejadian yang tidak diinginkan yang berhubungan dengan paparan terhadap lingkungan diagnosis atau kondisi perawatan medis.

\section{METODE}

Metode yang digunakan pada kajian ini adalah dengan menganalisis dari berbagai sumber bacaan. Metode yang digunakan pengkajian ini dengan mengumpulkan informasi dari berbagai referensi termasuk didalamnya hasil-hasil penelitian.

Referensi yang saya ambil dari jurnal online, tesis yang mengarah pada topik Pentingnya Mengoptimalkan Evaluasi Keselamatan Pasien dan pengerjaannya dengan cara membandingkan artikel satu dengan artikel yang lain.

\section{HASIL}

Hasil dari kajian ini, Rumah sakit merupakan layanan jasa yang memiliki peran penting dalam kehidupan masyarakat dalam bidang kesehatan. Keselamatan pasien merupakan inti dari mutu pelayanan kesehatan. Membangun budaya keselamatan pasien merupakan langkah awal dalam pengembangan keselamatan pasien. Budaya keselamatan pasien di rumah sakit merupakan bagian dari budaya organisasi, sehingga pengkajian tentang budaya organisasi diperlukan untuk menjadi panduan dalam mengembangkan keselamatan pasien. Upaya penerapan budaya keselamatan pasien bagi perawat pelaksana memerlukan peran supervisi untuk mewujudkan keselamatan pasien dalam pelayanan keperawatan di rumah sakit. Budaya keselamatan pasien adalah produk dari nilai, sikap, kompetensi dan pola perilaku individu dan kelompok yang menentukan komitmen, style dan kemampuan suatu organisasi pelayanan kesehatan terhadap program keselamatan pasien. Dimensi dalam budaya keselamatan pasien yaitu keterbukaan komunikasi, feedback dan komunikasi tentang kesalahan yang terjadi, frekuensi pelaporan kejadian, handoff dan transisi, dukungan organisasi untuk keselamatan pasien, nonpunitive respon to Error/respon tidak menghakimi 
pada kesalahan yang dilakukan, organizational learning pembelajaran berkelanjutan, persepsi keseluruhan mengenai keselamatan pasien, staffing, supervisor/harapan manajer dan tindakan yang dilakukan untuk meningkatkan keselamatan pasien, kerjasama lintas unit, kerjasama antar unit/dalam unit. Meningkatkan keamanan pasien harus menjadi prioritas tertinggi dari pemimpin layanan kesehatan dan manajer. Penerapan program keselamatan pasien lebih efektif dibandingkan dengan faktor-faktor lain dalam menurunkan angka kejadian insiden keselamatan pasien.

Peraturan Menteri Kesehatan Republik Indonesia No.691/MENKES/PERS/VIII/2011 tentang keselamatan pasien di rumah sakit, disebutkan bahwa keselamatan pasien di rumah sakit adalah suatu sistem dimana rumah sakit membuat asuhan pasien lebih aman yang meliputi asesmen risiko, identifikasi dan pengelolaan hal yang berhubungan dengan risiko pasien, pelaporan dan analisis insiden, kemampuan belajar dari insiden dan tidak lanjutnya serta implementasi solusi untuk meminimalkan timbul resiko dan mencegah terjadinya cedera yang disebabkan oleh kesalahan akibat melaksanakan suatu tindakan atau tidak mengambil tindakan yang seharusnya diambil. Pelayanan kesehatan adalah sebuah konsep yang digunakan dalam memberikan layanan kesehatan kepada masyarakat.

\section{- Standar Keselamatan Pasien Di Rumah Sakit}

Menurut Gerties dalam Rebbeca (2007) patient-center care terdiri dari 7 upaya keselamatan pasien :
a) Peduli terhadap nilai-nilai pasien, pencegahan dan pengendalian kebutuhannya
b) Melakukan koordinasi dan integrasi perawatan
c) Pendidikan, komunikasi dan informasi
d) Kenyamanan fisik
e) Dukungan emosi
f) Membuat pasien sebagai keluarga atau teman
g) Transition and continuity (keberlanjutan)

\section{- Standar keselamatan pasien tersebut terdiri dari tujuh standar yaitu :}

1. Hak pasien

2. Mendidik pasien dan keluarga

3. Keselamatan pasien dan kesinambungan pelayanan

4. menggunakan metode-metode peningkatan kinerja untuk melakukan evaluasi dan program peningkatan keselamatan pasien 
5. Peran kepemimpinan dalam meningkatkan keselamatan pasien

6. Mendidik staf tentang keselamatan pasien

7. Komunikasi merupakan kunci bagi staf untuk mencapai keselamatan pasien

\section{PEMBAHASAN}

Budaya Keselamatan pasien menurut NPSA (2004) secara garis besar ada empat komponen yaitu terbuka (open), adil (just), informatif dalam melaporkan kejadian yang terjadi(reporting) dan belajar dari kesalahan yang ada (learning). Bersikap terbuka dan adil berarti berbagai informasi secara terbuka dan bebas, dan perlakukn adil bagi perawat ketika terjadi sebuah kejadian. Informasi yang akurat membantu dalam pencegahan kejadian dari keselamatan pasien.

Budaya keselamatan pasien pada suatu organisasi menurut Agency For Healthcare Research and Quality (AHRQ) adalah produk dari individu dan kelompok yang merupakan nilai dari sikap, persepsi, kompetensi dan perilaku yang menimbulkan komitmen dan pola dari suatu manajemen kesehatan mengenai keselamatan pasien. Organisasi dengan budaya keselamatan pasien yang positif mempunyai karakteristik komunikasi saling terbuka dan percaya, serta persepsi yang sama mengenai pentingnya keselamatan pasien dan kenyamanan dalam pengukuran guna pencegahan. Rumah sakit sebagai organisasi pelayanan kesehatan berusaha untuk meningkatkan pertumbuhan budaya keselamatan pasien. Budaya keselamatan pasien adalah wajib dan seluruh pegawai bertanggung jawab terhadap keselamatan diri mereka sendiri, pasien dan pengunjung. Fokus budaya keselamatan yang baru adalah pembelajaran yang dilakukan setiap saat terhadap kesalahan yang terjadi. Mengubah budaya keselamatan pasien dari Blaming Culture (saling menyalahkan) menjadi safety culture merupakan kunci dalam peningkatan mutu pelayanan dan keselamatan pasien.

Penerapan budaya keselamatan pasien dimulai dengan melakukan survei tentang isuisu antara lain bagaimana kemampuan manajemen melihat ke depan dan berkomitmen dengan keselamatan pasien, bagaimana komunikasi antara staf dengan manajer, bagaimana sikap dan perilaku dalam melaporkan suatu kejadian, blaming dan pengumumannya dan bagaimana faktor-faktor dalam lingkungan kerja yang dapat mempengaruhi kinerja. Keselamatan pasien adalah pasien bebas dari haram/cidera yang tidak seharusnya terjadi atau bebas dari haram yang potensial akan terjadi (penyakit, cedera fisik/social/psikologis, cacat, kematian dll), terkait dengan pelayanan kesehatan. 
Tujuan dari langkah-langkah menuju keselamatan pasien ini adalah untuk mengidentifikasi pasien secara benar, meningkatkan komunikasi yang efektif, meningkatkan keamanan dari pengobatan risiko tinggi, mengeliminasi kesalahan penempatan, kesalahan pengenalan pasien, kesalahan prosedur operasi, mengurangi risiko infeksi yang berhubungan dengan pelayanan, dan mengurangi risiko pasien terluka karena jatuh.

- Tujuh langkah menuju keselamatan pasien sesuai dengan Peraturan Menteri Kesehatan Republik Indonesia Nomor 11 Tahun 2017 BAB III Penyelenggaraan Keselamatan Pasien pada ayat (2) huruf c terdiri dari :

1) Membangun kesadaran akan nilai keselamatan pasien, "ciptakan kepemimpinan \& budaya yang terbuka dan adil”

2) Memimpin dan dukung staf anda, "bangunlah komitmen dan fokus yang kuat dan jelas tentang keselamatan pasien di RS"

3) Mengintegrasikan aktivitas pengelolaan risiko, "serta lakukan identifikasi dan asesmen hal yang potensial bermasalah"

4) Mengembangkan sistem pelaporan, "pastikan staf agar dengan mudah dapat melaporkan kejadian/insiden serta RS mengatur pelaporan kepada KKP-RS”

5) Melibatkan dan berkomunikasi dengan pasien, "kembangkan cara-cara komunikasi yang terbuka dengan pasien"

6) Belajar dan berbagi pengalaman tentang keselamatan pasien, "dorong staf untuk melakukan analisis akar masalah untuk belajar bagaimana dan mengapa kejadian itu timbul"

7) Cegah cedera melalui implementasi sistem keselamatan pasien, "Gunakan informasi yang ada tentang kejadian/masalah untuk melakukan perubahan pada sistem pelayanan"

Rumah sakit harus mampu memberikan perlindungan terhadap keselamatan pasien, masyarakat, lingkungan rumah sakit, serta sumber daya manusia yang ada. Paradigma baru dalam sistem akreditasi KARS versi 2012, mengarahkan seluruh kegiatan pelayanan rumah sakit agar mampu memberikan pelayanan yang memenuhi standar kualitas serta jaminan rasa aman dan perlindungan terhadap dampak pelayanan yang diberikan dalam rangka pemenuhan hak-hak masyarakat akan pelayanan yang berkualitas serta aman. Keamanan pelayanan di Rumah Sakit salah satunya dimulai dari ketepatan identifikasi pasien. Kesalahan identifikasi 
pasien di awal pelayanan akan berdampak pada kesalahan pelayanan pada tahap selanjutnya. Rumah Sakit harus menjamin proses identifikasi ini berjalan dengan benar sejak pertama kali pasien di daftar. risiko keselamatan terjadi ketika terdapat ketidakcocokan antara pasien dengan item pelayanan yang seharusnya diterima, baik bersifat diagnostik, therapeutic maupun pelayanan pendukung lainnya. Kesalahan identifikasi pasien merupakan akar masalah adanya banyak kesalahan yang terjadi.

Penerapan program keselamatan pasien merupakan syarat untuk diterapkan di semua rumah sakit yang diakreditasi oleh komite akreditasi rumah sakit. Penyusunan program keselamatan pasien mengacu kepada Nine Life-Saving Patient Safety Solutions dari WHO Patient Safetyyang digunakan juga oleh komite keselamatan pasien rumah sakit dan dari joint commission internasional (JCI). Sasaran keselamatan pasien terdiri atas enam sasaran, yaitu ketepatan identifikasi pasien, peningkatan komunikasi yang efektif, peningkatan keamanan obat yang perlu diwaspadai (high alert), kepastian tepat lokasi, tepat prosedur, dan tepat pasien operasi, pengurangan risiko infeksi terkait pelayanan kesehatan, dan pengurangan resiko jatuh.

Reiman (2010) mengemukakan untuk meningkatkan keselamatan pasien memerlukan beberapa hal yaitu : (a) peningkatan kemampuan untuk belajar dari kesalahan, melalui sistem pelaporan yang lebih baik, (b) mengantisipasi kesalahan dan memeriksa terhadap kelemahan yang menyebabkan terjadinya kesalahan tersebut, (c) mengidentifikasi sumber daya yang ada, (d) perbaikan dalam berbagai sistem. pelaksanaan pelayanan yang berkaitan dengan manajemen mutu berbeda dari satu negara dengan negara lainnya, begitu juga dalam hal budayanya sehingga perlu untuk melakukan standarisasi internasional mengenai definisi, metode untuk pengukuran, dan pelaporan compatible efek samping pelayanan.

Salah satu strategi yang digunakan untuk mengurangi kejadian tidak diharapkan (adverse event) di suatu pelayanan kesehatan, yaitu dengan menstimulus budaya keterbukaan dan menstimulus sikap reflektif terhadap kesalahan yang dilakukan maupun terjadinya kejadian yang tidak diharapkan.

Konsep budaya keselamatan pasien dikembangkan dari konteks budaya keselamatandi dunia industri di mana budaya keselamatan pasien didefinisikan sebagai keyakinan nilai, perilaku, yang dihubungkan dengan keselamatan pasien dan dianut bersama oleh tenaga kesehatan yang berada di dalam ruang lingkuprumah sakit. Budaya keselamatan pasien merupakan suatu kondisi dimana budaya organisasi mendukung dan mempromosikan 
keselamatan pasien. Budaya keselamatan pasien merujuk dari keyakinan, nilai dan normanorma yang ditunjukkan oleh praktisi pelayanan kesehatan dan staf lain dalam suatu organisasi yang mempengaruhi tindakan dan sikapnya. Budaya keselamatan pasienmerupakan sesuatu yang bisa diukur dengan cara menghargai apa yang dilakukan oleh pegawai, dukungan yang diberikan dan penerimaan dari organisasi terhadap sesuatu yang terkait dengan keselamatan pasien.

\section{Aspek budaya keselamatan pasien}

Nilai budaya keselamatan pasien melalui tiga aspek :

1. Tingkat unit, mencakup : supervisor/manager action promoting safety, organizational learning-perbaikan berkelanjutan, kerjasama dalam unit di rumah sakit, komunikasi yang terbuka, umpan balik dan komunikasi mengenai kesalahan, respon tidak mempersalahkan terhadap kesalahan, dan manajemen ketenagakerjaan.

2. Tingkat rumah sakit, mencakup : dukungan manajemen terhadap upaya keselamatan pasien, kerjasama antar unit di rumah sakit, perpindahan transisi pasien.

3. Keluaran, mencakup persepsi keseluruhan stop di rumah sakit terkait keselamatan pasien, frekuensi pelaporan kejadian, peringkat keselamatan pasien, jumlah total laporan kejadian dalam 12 bulan terakhir.

\section{PENUTUP}

Menurut Permenkes No 56 Tahun 2014, Rumah Sakit adalah institusi pelayanan kesehatan yang menyelenggarakan pelayanan kesehatan perorangan secara Paripurna yang menyediakan pelayanan rawat inap, rawat jalan dan gawat darurat.

Menurut WHO Rumah Sakit adalah institusi pelayanan kesehatan yang mengorganisir staf medis, dan staf profesi lain, mempunyai fasilitas rawat inap pasien, dan memberikan pelayanan selama 24 jam sehari. Rumah sakit menyediakan pelayanan untuk kondisi pasien yang akut, pasien yang menuju kesembuhan maupun pasien yang berada dalam kondisi perawatan terminal, dengan menggunakan pelayanan diagnostik dan kuratif. Sebagai perawat harus melaksanakan tujuh langkah-langkah menuju keselamatan pasien dengan tepat. Agar terciptanya budaya keselamatan pasien di rumah sakit, meningkatnya akuntabilitas Rumah Sakit terhadap pasien dan masyarakat, terlaksananya program-program pencegahan sehingga tidak terjadi pengulangan KTD.

\section{REFERENSI}


1. Anggraeni,Dewi, Lukman Hakim, Cecilia Widijiati.2014.Evaluasi Pelaksanaan Sistem Identifikasi Pasien Di Instalasi Rawat Inap Rumah Sakit. Jurnal Kedokteran Brawijaya. Vol: 28(1). 99-104.

2. Diny Vellyana.2015. Analisis Budaya Kselamatan Pasien Dalam Pelayanan Kesehatan Di RS PKU Muhammadiyah Unit II Gamping.Tesis. Program Studi Manajemen Rumah Sakit Program PascaSarjana Universitas Muhammadiyah Yogyakarta.

3. Irawan,dkk.2017. Hubungan Supervisi dengan Penerapan Budaya Keselamatan Pasien Di Ruang Rawat Inap Rumah Sakit XX. Vol: 5(1). 241-254.

4. Iriviranty.2015. Analisis Budaya Organisasi dan Budaya Keselamatan Pasien Sebagai Langkah Pengembangan Keselamatan Pasien Di RSIA Budi Kemuliaan Tahun 2014. Jurnal ARSI. Vol: 1(3). 196-206.

5. Kusharwanti,Wara,dkk.2014. Pengoptimalkan Peran Apoteker Dalam Pemantauan dan Evaluasi Insiden Keselamatan Pasien. Jurnal Farmasi Klinik Indonesia. Vol: 3(3). 67-76.

6. Kusumaningsih,Dewi.2017. Optimalisasi Penerapan Bar-Code Medication Administration (BCMA) Sebagai Upaya Peningkatan Keselamatan Pasien:Literature Riview. Jurnal Kesehatan Holistik. Vol: 11(1). 9-13.

7. Muhammad Zulkani.2018. Budaya Keselamatan Pasien dalam Insiden KTD dan KNC Di Instalasi Laboratorium RSUD INCHE ABDOEL MOEIS SAMARINDA Tahun 2017. Tesis. Program PascaSarjana Fakultas Kesehatan Masyarakat Universitas Hasanuddin.

8. Sheikh,F,Garcia, N.A,Jamal, D dan Abdo,A.2014. Patient Safety Culture in a Large Teaching Hospital in Riyadh:baseline assessment,comparative analysis and opportunities for improvement. BMC Health Services Research, 14,122.

9. Simamora, R. H., \& Fathi, A. (2019). The Influence Of Training Handover Based SBAR Communication For Improving Patients Safety. Indian Journal of public health research \& development, 10(9), 1280-1285.

10. Sorra J, Gray L,Streagle S, Famolaro T, Yount N dan Behm J.2016.AHRQ Hospital Survey on Patient Safety Culture 2016 user comparative database report, AHRQ Publication. 
11. Tanti Arini.2018. Budaya Keselamatan Pasien Berbasis Pemberdayaan Struktural dengan Kepuasan Kerja Perawat. Tesis. Program Studi Magister Keperawatan Fakultas Keperawatan Universitas Airlangga. 